\section{RAPID IMPROVEMENT IN BIPOLAR II DEPRESSION INDUCED BY LOW-DOSE LAMOTRIGINE AUGMENTA- IION: TWO CASE REPORTS}

\section{To the Editor:}

The role of antidepressants in the treatment of the depressed phase of bipolar disorder remains controversial due to risk of induction of hypomania, mixed episodes, and rapid cycling. ${ }^{1,2}$ In addition, antidepressants may not be as efficacious in the management of the depressed phase of bipolar disorder as they are in the management of major depressive disorder. Many experts believe that the treatment of bipolar depression should include antidepressants in combination with an antimanic drug such as lithium. ${ }^{3}$ However, few studies are available that guide the next best treatment if a mood stabilizer plus an antidepressant fails to help patients with bipolar depression. The limited available data suggests that patients can be switched to either electroconvulsive therapy ${ }^{4}$ or monoamine oxidase inhibitors (MAOls). ${ }^{5,6}$ Other options include combining mood stabilizers, switching to the combination of olanzapine and fluoxetine, ${ }^{8}$ and switching to quetiapine. ${ }^{9}$

Recently, lamotrigine has been found to be efficacious in the long-term management of bipolar disorder (especially in delaying depressive recurrence), either as a monotherapy or adjunctive therapy, but its efficacy in the acute treatment of bipolar depression is less clear. ${ }^{10,11}$ However, to our knowledge, there is no literature available that addresses rapid improvement induced by low-dose lamotrigine augmentation in bipolar II depression. Here, we report two cases of bipolar II depressed patients who did not respond to two different antidepressant trials that lasted for $\geq 8$ weeks, but subsequently showed rapid improvement after low-dose lamotrigine augmentation.

\section{Case 1}

Mrs. M was a 45-year-old married woman with a primary school education who was admitted to our hospital. She had suffered from bipolar II disorder for the previous 5 years and had experienced three depressive episodes and one hypomanic episode within that time. The first episode of her illness was a depressive episode at 40 years of age. She had been treated with various atypical antipsychotics, mood stabilizers including lithium, and various antidepressants including paroxetine, escitalopram, and sertraline during this period.

Upon examination, she was found to suffer from severe pervasive sadness; anhedonia; hypersomnia; severe psychomotor retardation; feelings of worthlessness; distractibility; occasional passive suicidal ideation; and decreased energy, concentration, appetite, and self-esteem. She remained in bed most of the time, rarely cared for herself, and could not work. She experienced these symptoms on most days and nearly every day during the month prior to admission. This was the fourth depressive episode of her illness. Her 17-item Hamilton Depression Rating Scale $\left(H A M-D_{17}\right)^{12}$ score was 31. An 8-week trial of escitalopram failed to consistently improve her depression. Subsequently, her medication was replaced by venlafaxine, which has a more rapid onset of action and is often used in bipolar depression. Venlafaxine was started at a dose of $75 \mathrm{mg} /$ day and gradually increased to $300 \mathrm{mg} /$ day within 2 weeks. At week 6 of venlafaxine treatment, there was no significant improvement in her depressive symptoms. Her HAM-D total score was 26. Therefore, lithium was added to her medication and gradually increased to $900 \mathrm{mg} /$ day (the mean plasma levels were 0.77 ). Since the clinical response at week 4 after lithium augmentation was only partial, $25 \mathrm{mg} / \mathrm{day}$ lamotrigine was added to this regimen. The patient responded to lamotrigine after 3 days of treatment while on a dose of $25 \mathrm{mg} /$ day. The patient reported increased energy, improvement in hypersomnia, a greater ability to concentrate, and increased appetite.

After 1 week of treatment, there was a significant clinical improvement in her depression. Her HAM-D total score was 8. The individual symptoms that showed rapid improvements (week 1) were depressed mood (HAM-D item 1), feelings of guilt (HAM-D item 2), suicide (HAM-D item 3), work and activities (HAM-D item 7), and anxiety psychic (HAM-D item 10). On day 9 of combination therapy, her depressive symptoms remitted completely with no evidence of adverse effects. The final HAM-D total score was 2. In addition, there were no symptoms suggestive of either a mixed episode or hypomanic state. The patient continued this combination regimen, including venlafaxine $300 \mathrm{mg} /$ day, lithium 900 $\mathrm{mg} /$ day, and lamotrigine $25 \mathrm{mg} /$ day, without recurrence of depression or emergence of hypomania or adverse effects for 2 months.

\section{Case 2}

Mrs. G was a 41-year-old married woman with a high school education who was admitted to our inpatient clinic. She had suffered from bipolar II disorder for the previous 7 years and had experienced six depressive episodes and two hypomanic episodes within that time. The first episode of her illness was a depressive episode at 34 years of age. She had been treated with various antipsychotics (including quetiapine, olanzapine, and ris- peridone), mood stabilizers (including lithium), and antidepressants (including sertraline, venlafaxine, and escitalopram) during this period. She had been regularly maintained on a treatment regimen (including lithium $1,200 \mathrm{mg} / \mathrm{day}$ and quetiapine $200 \mathrm{mg} / \mathrm{day}$ ) for 2 months when she experienced a depressive episode. The mean plasma level of lithium was 0.82 . Upon examination, she was found to suffer from severe pervasive sadness, anhedonia, insomnia, moderate psychomotor retardation, feelings of worthlessness, distractibility, recurrent suicidal ideation, somatic symptoms, and somatic anxiety as well as decreased energy, concentration, and appetite. Her HAM-D total score was 34 . In light of this, escitalopram was added to the ongoing lithium and quetiapine treatment. An 8-week escitalopram trial failed to consistently improve her depression. Subsequently, her medication was replaced with sertraline. Sertraline was started at a dose of $50 \mathrm{mg} / \mathrm{day}$ and gradually increased to $150 \mathrm{mg} /$ day. After 8 weeks of sertraline treatment, there was no significant improvement in her depressive symptoms. Her HAM-D total score was 28. Subsequently, $25 \mathrm{mg} /$ day lamotrigine was added to her treatment regimen. The patient responded to lamotrigine after $\sim 2$ days of treatment while on a dose of $25 \mathrm{mg} /$ day. The patient experienced a significant improvement in HAM-D scores for suicide, insomnia, retardation, general somatic symptoms, and anxiety somatic. Within 1 week, the patient's HAM-D total score dramatically decreased from 28 to 9 . In addition, there were no symptoms suggestive of either a mixed episode or hypomanic state. The patient continued this combination regimen, including sertraline 150 $\mathrm{mg} /$ day, lamotrigine $25 \mathrm{mg} /$ day, lithium 1,200 $\mathrm{mg} /$ day, and quetiapine $200 \mathrm{mg} /$ day, without recurrence of depression or emergence of hypomania or adverse effects for 2 months.

\section{Discussion}

Previous studies have suggested that lamotrigine, used alone or in combination with other psychotropic drugs, is safe and effective in the management of bipolar II depression, but not mania. ${ }^{10,13,14}$ However, for the acute treatment of bipolar II depression, lithium, lamotrigine, and quetiapine have been recommended as second-line options and there is insufficient information to recommend any medication as a first-line treatment. ${ }^{15}$

The exact mechanism by which lamotrigine exerts its action has not been completely elucidated, but a number of putative neurochemical effects have been postulated. In forced swim test, increased swimming and decreased immobility indicate antidepressant-like effect. It has been demonstrated that, when combined with veratrine, a $\mathrm{Na}^{+}$ 
channel opener, the antidepressant-like effect of lamotrigine is reversed, but that the antidepressant-like effect of imipramine, desipramine, and paroxetine is not changed. This finding indicates that the mechanism of action of lamotrigine is different from that of antidepressants. ${ }^{11}$ It has been suggested that the antidepressant-like effect of lamotrigine is related to the noradrenergic system, likely due to an activation of $\alpha_{1}$ - and $\alpha_{2}$-postsynaptic adrenoceptors, and serotonergic systems. ${ }^{16,17}$ Muck-Seler and colleagues $^{18}$ found that lamotrigine has an effect on platelet MAO-B activity in patients with bipolar depression, and they suggested that its in vivo MAO-B inhibiting effect might have contributed, in part, to its antidepressant activity. On the other hand, there is evidence that bipolar depression is characterized by increased glutamate coupled with increased energy expenditure. Evidence has also suggested that in patients with refractory affective disorder, excitatory amino acids are dysregulated. Lamotrigine appears to reduce glutamine levels associated with treatment remission. This may be another action mechanism of lamotrigine in bipolar depression treatment. ${ }^{19}$

In the present study, low-dose lamotrigine induced rapid improvement from depressive symptoms in bipolar II disorder; however, the mechanism behind this result is unclear. Its broader action mechanism (with effects on noradrenergic, dopaminergic, serotonergic, and glutamatergic neurotransmission, MAO-B inhibiting effect, and the effects of sodium and calcium channel) may be an explanation for the rapid and sustained improvement induced by its low-dose augmentation in the reported cases. The literature suggests that atypical antipsychotics may induce a rapid improvement in individuals with depression. For example, rapid improvement associated with the augmentation strategy has been described in relation to olanzapine and risperidone in previous studies. ${ }^{20,21}$ These studies suggest that the augmentation effect of atypical antipsychotics may depend on the antidepressant being in place, a mechanism postulated to explain lithium augmentation of antidepressant drugs in unipolar depression. De Montigny and colleagues, ${ }^{22}$ describing a case series of eight patients who responded rapidly to lithium introduction after having failed to respond to a tricyclic antidepressant (TCA), suggested that TCA pretreatment sensitized the serotonin receptor to create an antidepressant effect and then lithium increased the efficacy of the central serotonergic system. Similarly, such a model may account for the substantive antidepressant responses reported when low-dose lamotrigine was added to antidepressant medication in patients who did not respond to the combination of an antidepressant and lithium.

On the other hand, Calabrese and colleague ${ }^{23}$ demonstrated that lamotrigine monotherapy did not demonstrate efficacy in the acute treatment of bipolar depression in four out of five placebo controlled clinical studies. However, it is important to note that lamotrigine was used as a monotherapy in their study while it was used as an adjunctive therapy in the reported cases. Lamotrigine has mostly been studied as monotherapy in bipolar depression. Recently, van der Loos and colleagues ${ }^{24}$ compared the acute effects of lamotrigine and placebo as add-on therapy to ongoing treatment with lithium in patients with a Diagnostic and Statistical Manual of Mental Disorders, Fourth Edition bipolar I or II disorder and had a major depressive episode while receiving lithium treatment $(0.6$ $1.2 \mathrm{mmol} / \mathrm{L}$ ). They showed that lamotrigine was effective and safe as add-on treatment to lithium in the acute treatment of bipolar depression. In addition, it has been demonstrated that the combination of lithium and lamotrigine was effective for acute depressive symptoms in about half of treatmentresistant bipolar patients. ${ }^{25}$ Therefore, this may be another factor that contributes to the rapid improvement related to the addition of low dose lamotrigine in the reported cases.

Some studies have suggested that tachyphylaxis (which refers to the gradual loss of efficacy after repeated antidepressant exposures over time) ${ }^{26}$ may be influenced by antidepressant class, ${ }^{27}$ with the greatest proportion occurring during selective serotonin reuptake inhibitor therapy. Moreover, some studies have suggested that tachyphylaxis may occur more frequently in patients with bipolar II depressive episode ${ }^{28,29}$ and that these patients may be more likely to develop treatment-resistant depression. ${ }^{29,30}$ Although some authors propose that lamotrigine, used alone or in combination with other psychotropic drugs, is safe and effective in the management of treatment-resistant bipolar II depression, ${ }^{10,13}$ no study has examined the effect of lamotrigine on tachyphylaxis associated with long-term antidepressant exposure.

\section{Conclusion}

Depression in bipolar illness is an important syndrome. It occupies a large fraction of the patients' lives and is related to significant morbidity and mortality. In spite of its high prevalence, bipolar II depression and its treatment strategies remain poorly understood. This report provides further evidence that lamotrigine used in combination with other psychotropic drugs is safe and effective in the management of bipolar II depression. These cases also highlight the possibility of lamotrigine in low doses acting as a quick antidepressant, even when added to other mood stabilizers. However, the mechanisms behind the rapid improvement induced by lamotrigine in the reported cases remains unclear. Controlled studies are necessary to understand the pharmacologic mechanisms underlying rapid improvement in bipolar II depression following treatment with low-dose lamotrigine.

Sincerely,

Omer Akil Ozer, MD

Okan Ekinci, MD

Ali Caykoylu, MD

\section{References}

1. Ghaemi SN, Ko JY Goodwin FK "Cade's disease" and beyond: misdiagnosis, antidepressant use, and a proposed beyond: misdiagnosis, antidepressant use, and a proposed
definition for bipolar spectrum disorder. Can J Psychiatry. 2002:47:125-134.

2. Leverich GS, Altshuler LL, Frye MA, et al. Risk of switch in mood polarity to hypomania or mania in patients with bipolar depression during acute and continuation trials of venlafaxine, sertraline, and bupropion as adjuncts to mood stabilizers. $A m$ sertraline, and bupropion as a
Psychiatry. 2006;163:232-239.

3. Altshuler LL, Suppes T, Black DO, et al. Lower switch rate in depressed patients with bipolar II than bipolar I disorder treated adjunctively with second generation antidepressants. Am J Psychiatry. 2006;163:313-315.

4. Homan S, Lachenbruch PA, Winkur G, et al. An efficacy study of electroconvulsive therapy and antidepressants in the treatment of primary depression. Psychol Med. 1982;12:615-624.

5. Himmelhoch JM, Thase ME, Mallinger AG, et al. Tranylcypromine versus imipramine in anergic bipolar depression. Am J Psychiatry. 1991;148:910-916.

6. Thase ME, Mallinger AG, McKnight D, et al. Treatment of imipramine-resistant recurrent depression, IV: a double- blind crossover study of tranylcypromine for anergic bipolar depression. Am J Psychiatry. 1992;149:195-198.

7. Young LT, Joffe RT, Robb JC, et al. Double-blind comparison of addition of a second mood stabilizer versus an antidepressant to an initial mood stabilizer for treatment of patients with bipolar depression. Am J Psychiatry. 2000;157:124-126.

8. Tohen M, Vieta E, Calabrese J, et al. Efficacy of olanzapine and olanzapine-fluoxetine combination in the treatment of bipolar I depression. Arch Gen Psychiatry. 2003;60:1079-1088.

9. Calabrese JR, Keck PE Jr, Macfadden W, et al. (BOLDER Study Group): A randomized, double-blind, placebo-controlled trial of quetiapine in the treatment of bipolar I or II depression. $A m ~ J$ Psychiatry. 2005:162:1351-1360.

10. Sharma V, Khan M, Corpse C. Role of lamotrigine in the management of treatment-resistant bipolar II depression: a chart review. J Affect Disord. 2008;111(1):100-105.

11. Prica C, Hascoet M, Bourin M. Antidepressant-like effect of lamotrigine is reversed by veratrine: a possible role of sodium channels in bipolar depression. Behav Brain Res. 2008;191(1):49-54

12. Hamilton, M. A rating scale for depression. J Neurol Neurosurg Psychiatry. 1960;23:56-62.

13. Nierenberg AA, Ostacher MJ, Calabrese JR, et al. Treatmentresistant bipolar depression: a STEP-BD equipoise randomized effectiveness trial of antidepressant augmentation with lamotrigine, inositol, or risperidone. Am J Psychiatry. 2006; 163(2):210-216.

14. Schaffer A, Zuker P, Levitt A. Randomized, double-blind pilot trial comparing lamotrigine versus citalopram for the treatment of bipolar depression. J Affect Disord. 2006;96:95-99.

15. Yatham LN, Kennedy SH, O'Donovan C, et al. Canadian Network for Mood and Anxiety Treatments (CANMAT) guidelines for the management of patients with bipolar disorder: update 2007. Bipolar Disord. 2006; 8:721-739.

16. Consoni FT, Vital MA, Andreatini R. Dual monoamine modulation for the antidepressant-like effect of lamotrigine in the modified forced swimming test. Eur Neuropsychopharmacol. 2006;16(6):451-458

17. Kaster MP, Raupp I, Binfaré RW, et al. Antidepressant-like effect of lamotrigine in the mouse forced swimming test: evidence for the involvement of the noradrenergic system. Eur J Pharmacol 2007:565:119-124.

18. Muck-Seler D, Sagud M, Mustapic M, et al. The effect of lamotrigine on platelet monoamine oxidase type B activity in 
patients with bipolar depression. Prog Neuropsychopharmacol Biol Psychiatry. 2008;32(5):1195-1198.

19. Frye MA, Watzl J, Banakar $S$, et al. Increased anterior cingulate/ medial prefrontal cortical glutamate and creatine in bipola depression. Neuropsychopharmacology. 2007;32(12):2490-2499.

20. Ostroff RB, Nelson JC. Risperidone augmentation of selective serotonin reuptake inhibitors in major depression. J Clin Psychiatry. 1999; 60:256-259

21. Parker $\mathrm{G}$. Olanzapine augmentation in the treatment of melancholia: the trajectory of improvement in rapid responders. Int Clin Psychopharmacol. 2002:17:87-89.

22. De Montigny C, Grunberg F, Mayer A, et al. Lithium induces rapid relief of depression in tricyclic antidepressant drug nonresponders. Br J Psychiatry. 1981;138:252-256,

23. Calabrese JR, Huffman RF, White RL, et al. Lamotrigine in the acute treatment of bipolar depression: results of five double-blind, placebo-controlled clinical trials. Bipolar Disord. 2008;10(2):323-333.

24. van der Loos ML, Mulder PG, Hartong EG, et al. Efficacy and safety of lamotrigine as add-on treatment to lithium in bipola depression: a multicenter, double-blind, placebo-controlled trial. J Clin Psychiatry. 2009;70(2):223-231.

25. Ghaemi SN, Schrauwen E, Klugman J, et al. Long-term lamotrigine plus lithium for bipolar disorder: One year outcome. J Psychiatr Pract. 2006;12(5):300-305

26. Leykin Y, Amsterdam JD, DeRubeis RJ, et al. Progressive resistance to SSRI therapy but not to cognitive therapy in the treatment of major depression. J Consult Clin Psychol. 2007;75(2):267-276.

27. Posternak MA, Zimmerman M. Dual reuptake inhibitors incur lower rates of tachyphylaxis than selective serotoni reuptake inhibitors: A retrospective study. J Clin Psychiatry. 2005;66:705-707.

28. Sharma V. Loss of response to antidepressants and subsequen refractoriness: diagnostic issues in a retrospective case series. J Affect Disord. 2001;64 (1):99-106.

29. Sharma V, Khan M, Smith A. A closer look at treatment resistant depression: is it due to a bipolar diathesis? J Affect Disord. 2005:84:251-257

30. Ei-Mallakh, RS, Karippot, A. Antidepressant-associated chronic irritable dysphoria (ACID) in bipolar disorder: a case series. Affect Disord. 2005;84:267-272

Dr. Ozer is specialist of psychiatry, Dr. Ekinci is research assistant of psychiatry, and Dr. Caykoylu is professor and clinical director in the Departmen is professor and clinical director in the Department Hospital in Ankara, Turkey.

Faculty Disclosures: Drs. Ozer, Ekinci, and Caykoylu report no affiliation with or financial interest in any organization that may pose a conflict of interest.

Submitted for publication: January 21, 2009; Accepted for publication: August 5, 2009.

Please direct all correspondence to: Ankara Ataturk Egitim ve Arastırma Hastanesi Psikiyatri Klinigi, 06520 Bilkent/Ankara, Turkey. Tel: +90-312-2912525, Fax Bilkent/Ankara, Turkey. Tel: +90-312-2912525, Fax
+90-312-2912705; E-mail: drokanekinci@yahoo.com.

\section{A SEVERE CASE OF BUPROPION HYDROCHLORIDE EXTENDED-RELEASE MONO- THERAPY-ASSOCIATED VISUAL HALLUCINATIONS AND DELIRIUM IN A FEMALE PATIENT WITH MAJOR DEPRESSIVE DISORDER}

\section{To the Editor:}

Bupropion is thought to exert antidepressant effects via inhibition of dopamine and norepinephrine reuptake. ' Several recent reports have suggested that bupropion may promote the development of psychotic symptoms such as delusions and hallucinations in various patient populations. For example, bupropion treatment has been associated with delirium characterized by disorganized thinking, memory impairment, fear, and agitation without disorientation, delusions, hallucinations, or other perceptual distortions ${ }^{2}$; psychotic episodes due to bupropion overdose $\mathrm{e}^{3-7}$; paranoid delusions and hallucination after combination with other agents ${ }^{8-10}$; tactile hallucinations ${ }^{11}$; and psychosis in patients receiving low-dose bupropion with comorbid psychiatric and/ or medical disorders. ${ }^{12-15}$ Given the known relationship between enhanced dopaminergic function and psychotic symptoms, ${ }^{16}$ exacerbation or precipitation of psychotic symptoms by modulation of dopamine transmission is perhaps unsurprising. However, to our knowledge, there have been no reports of the combined development of visual hallucinations and a delirious episode associated with the slow titration of bupropion hydrochloride extended-release (bupropion $\mathrm{XL}$ ) monotherapy. This case report describes a patient presenting with major depressive disorder who suffered from visual hallucinations and delirium after titration of bupropion XL from $150 \mathrm{mg} /$ day to $300 \mathrm{mg} /$ day.

Ms. A was a 28-year-old woman with no family history of psychiatric disorders, who presented with a major depressive episode that had persisted for 2 months. She had no clinically significant comorbid medical or psychiatric conditions. Her depressive symptoms were moderate and without psychotic features, consisting primarily of depressed mood, lack of energy, loss of interest, tearfulness, decreased motivation, fatigue, loss of appetite, and hopelessness. She had no previous exposure to antidepressants. After the patient was briefed on the potential benefits and risks of bupropion, an initial 2-week course of bupropion XL $150 \mathrm{mg} /$ day was prescribed, in addition to twice daily alprazolam 0.25 $\mathrm{mg} /$ day. At the time of her next visit, Ms. A's depressive symptoms had responded a bit to the initial bupropion XL dose; specifically, she reported improvement in energy levels and concentration. She had no issues with tolerability, with the exception of mild sleep disturbance, and thus the dose of bupropion XL was increased to $300 \mathrm{mg} /$ day. Four days after she began taking the increased dose of bupropion $\mathrm{XL}$, she saw a group of ants crawling on a wall and became disoriented with associated psychomotor slowing At this point she was brought to the emergency room by her boyfriend and mother Neurological and neurosurgical consultation ruled out any potential organic causes. After admission, bupropion XL was immediately discontinued, and she was treated conservatively, without neuroleptics. Her condition began to improve shortly thereafter (hospital day 2); she had completely recovered by hospital day 5 without any residual symptoms, and was discharged.
The present case is the first to report the combined clinical manifestation of visual hallucinations and delirium associated with bupropion XL monotherapy after a dose increase from $150 \mathrm{mg} /$ day to $300 \mathrm{mg} /$ day.

Previous reports of transient psychotic symptoms due to bupropion predominantly involved cases of overdose, ${ }^{3-7}$ combination therapy, ${ }^{8,9,14}$ or high therapeutic doses, ${ }^{10,17-20}$ with patients frequently presenting with comorbid psychiatric and/or medical disorders. An interesting point is that the majority of these cases involved female patients, suggesting an increased vulnerability of the female gender to bupropion-induced psychotic symptoms. Although the exact mechanism underlying the development of psychosis remains unclear, the most likely possibilities include alterations in dopaminergic neurotransmission and effects arising from the structural similarities of bupropion and amphetamine. According to a previous report, ${ }^{17}$ risk factors for bupropion-associated psychosis include a history of psychotic episodes, comorbid medical disorders, combination of psychotropic drugs, concurrent use of a dopaminergic agent, and advanced age. Contributing factors to delirium may include increased dopaminergic activity, interaction with other medications, and accumulation of bupropion's active metabolite, hydroxybupropion. ${ }^{21}$

Earlier studies are largely similar to our case report and suggest that clinicians need to carefully monitor symptomatic changes in patients after starting bupropion treatment. The most notable point in the present case is the simultaneous onset of visual hallucinations and delirium that began four days after increasing the dose of bupropion $\mathrm{XL}$, and disappeared completely upon cessation of bupropion treatment. Hence, we cautiously suggest that bupropion XL may have a dose-dependent propensity for inducing acute psychotic symptoms mentioned in previous reports ${ }^{12}$ and produced by other agents. ${ }^{22}$ There have been no cases reporting the simultaneous onset of delirium and psychosis following bupropion treatment. However, our evidence suggests the possibility of more severe forms of clinical outcome, even after slow titration of bupropion XL. Furthermore, the patient was psychotropic-naive and had no comorbid diseases, reducing the likelihood of dopaminergic system sensitization due to concurrent medications. However, it is also plausible that individuals vary in their susceptibility to drug-induced psychosis, perhaps relating to their sensitivity to modulation of dopaminergic neurotransmission. Although the concurrent administration of alprazolam is unlikely to have influenced our results, it should be acknowledged, as ben- 
zodiazepines are also related to development of psychosis, delirium, and behavioral toxicity. ${ }^{23}$ Possible influences of specific genetic polymorphisms, particularly those relating to the pharmacokinetic and pharmacodynamic properties of bupropion XL or of the patient's premorbid personality traits should be also considered. With respect to treating the patient's depressive symptoms after the adverse reaction to bupropion $\mathrm{XL}$, switching to a different class of drugs, such as selective serotonin reuptake inhibitors, serotonin norepinephrine reuptake inhibitors, or norepineprhine and specific serotonergic antidepressants would probably be beneficial.

This case suggests that patients treated with bupropion $\mathrm{XL}$ should be carefully monitored, particularly when certain risk factors are present, and treatment should be tailored based on the potential vulnerability of the patient to psychosis.

Sincerely,

Chi-Un Pae, MD, PhD

\section{References}

Ascher JA, Cole J0, Colin JN, et al. Bupropion: a review of its mechanism of antidepressant activity. J Clin Psychiatry. 1995;56(9):395-401.

2. Dager SR, Heritch AJ. A case of bupropion-associated delirium J Clin Psychiatry. 1990:51(7):307-308.

3. Wang TS, Shiah IS, Yeh CB, Chang CC. Acute psycho- sis following sustained release bupropion overdose. Prog Neuropsychopharmacol Biol Psychiatry. 2005;29(1):149-151.

4. Hansen MB, Rasmussen KB, Braendholt V. [Acute psychosis following bupropion overdosage]. Ugeskr Laeger. 2008;170(46):3777-3778

5. Tracey JA, Cassidy N, Casey PB, Ali I. Bupropion (Zyban) toxicity. Ir Med J. 2002;95(1):23-24.

6. Shepherd G, Velez LI, Keyes DC. Intentional bupropion overdoses. J Emerg Med. 2004:27(2):147-151.

7. Spiller HA, Bosse GM, Beuhler M, Gray T, Baker SD. Unintentional ingestion of bupropion in children. J Emerg Med. In Press.

8. Pittenger C, Naungayan C, Kendell SF, et al. Visual hallucinations from the addition of riluzole to memantine and bupropion. J Clin Psychopharmacol. 2006;26(2):218-220.

9. Filteau MJ, Leblanc J, Lefrancoise S, Demers MF. Visual and auditory hallucinations with the association of bupropion and valproate. Can J Psychiatry. 2000:45(2):198-199.

10. Ames D, Wirshing WC, Szuba MP. Organic mental disorders associated with bupropion in three patients. J Clin Psychiatry. 1992;53(2):53-55.

11. Charuvastra A, Yaeger D. Tactile hallucinations associated with therapeutic doses of bupropion in 2 patients. J Clin Psychiatry. 2006:67(11):1820-1821.

12. Bailey $\mathrm{J}$, Waters $\mathrm{S}$. Acute psychosis after bupropion treatment in a healthy 28-year-old woman. J Am Board Fam Med. 2008:21(3):244-245.

13. Liu CY, Chien YS. Perceptual disturbances associated with low-dose bupropion sustained-release treatment. J Clin Psychopharmacol. 2007;27(5):543-544.

14. Javelot H, Baratta A, Weiner L, et al. Two acute psychotic episodes after administration of bupropion: a case of involuntary rechallenge. Pharm World Sci. 2009:31(2):238-240.

15. Hahn M, Hajek T, Alda M, Gorman JM. Psychosis induced by low-dose bupropion: sensitization of dopaminergic system by past cocaine abuse? J Psychiatr Pract. 2007;13(5):336-338.

16. Tost $H$, Alam T, Meyer-Lindenberg A. Dopamine and psychosis: Theory, pathomechanisms and intermediate phenotypes. Neurosci Biobehav Rev. In Press.

17. Howard WT, Warnock JK. Bupropion-induced psychosis. Am J Psychiatry. 1999;156(12):2017-2018

18. Golden RN, James SP, Sherer MA, Rudorfer MV, Sack DA Potter WZ. Psychoses associated with bupropion treatment Am J Psychiatry. 1985;142(12):1459-1462.

19. Becker RE Dufresne RL Perceptual changes with bupropion, novel antidepressant. Am J Psychiatry. 1982;139(9):1200-1201.
20. Neumann M, Livak V, Paul HW. [Acute psychosis after administration of bupropion hydrochloride (Zyban)]. Psychiatr Prax. 2004;31(Suppl 1):S140-141

21. Chan $\mathrm{CH}$, Liu HC, Huang MC. Delirium associated with concomitant use of low-dose bupropion sustained release and fluoxetine. J Clin Psychopharmacol. 2006;26(6):677-679.

22. Pae CU, Marks DM, Han C, Patkar AA. A case of transient hallucination with ropinirole augmentation antidepressant in a patient with treatment-resistant depression: Is there differentia effect of ropinirole dose on developing psychotic symptom? Prog Neuropsychopharmacol Biol Psychiatry. 2008;32(4):1087-1088.

23. Lonergan E, Luxenberg J, Areosa Sastre A. Benzodiazepines for delirium. Cochrane Database Syst Rev. 2009:4:CD006379.

Dr. Pae is associate professor in the Department of Psychiatry at Bucheon St. Mary's Hospital, The Catholic University of Korea College of Medicine, in the Republic of Korea, and adjunct associate professor in the Department of Psychiatry at Duke University Medical Center in Durham, North Carolina.

Faculty Disclosure: Dr. Pae has received research grants, honoraria, and speaker's fees from AstraZeneca Korea, Eli Lilly and Company Korea, GlaxoSmithKline, GlaxoSmithKline Korea, Janssen Pharmaceuticals Korea, Korean Institute of Science and Technology Evaluation and Planning, Korean Research Foundation, Otsuka International Asia and Arabia, Otsuka Korea Pharmaceuticals, Otsuka Pharmaceutical Development and Commercialization, and Wyeth Korea and Catholic Medical Center.

Submitted for publication: October 6, 2009; Accepted for publication: January 13, 2010.

Please direct all correspondence to: Chi-Un Pae, MD, PhD, Department of Psychiatry, Bucheon St. Mary's Hospital, The Catholic University of Korea College of Medicine, 2 Sosa-Dong, WonmiGu, Bucheon 420-717, Kyeonggi-Do, Republic of Korea, Tel: 82-32-340-0675, Fax: 82-2-6442-2789, E-mail: pae@catholic.ac.kr. 